\title{
EL “LADO DE B” DE LA ESCRITURA: CRONISTAS Y EMPLEADOS*
}

\author{
Claudia Darrigrandi Navarro**
}

\begin{abstract}
Resumen
A partir de un corpus de crónicas publicadas en la prensa chilena desde la primera mitad del XX hasta mediados del mismo, este artículo está centrado en el acto de escritura -desde el momento de sentarse a escribir-, así como también en las motivaciones y hechos que la anteceden a este inicio. Por un lado, Hernán Díaz Arrieta (Alone) a través de distintos medios de prensa, como también Joaquín Edwards Bello, desde su tribuna en La Nación, orientan a quienes quieren ser escritores. Por otro, Jenaro Prieto, Teófilo Cid y Arturo Méndez Carrasco hablan desde su rol de empleados de escritorio, en el que el ejercicio escritural es solo la principal característica de sus trabajos y que no necesariamente tienen relación con la literatura y/o el periodismo.
\end{abstract}

Palabras clave: escritura, crónica chilena, periodismo, cronistas, empleados.

\section{"THE DOWN SIDE OF WRITING": CHRONICLERS AND EMPLOYEES}

\begin{abstract}
This article focuses on the act of writing as it is portrayed in a number of chronicles published in Chilean press in the first half and middle of Twentieth Century. The analysis considers basic gestures such as sitting in front of typewriter as well as personal motivations and facts that precede it. On the one hand, this article discusses Hernán Díaz Arrieta's (Alone) chronicles, who published in many newspapers, journals and magazines, and some other written by Joaquín Edwards Bello, from his weekly contribution in La Nación. Both of them give advice to those who want to become writers. On the other hand, Jenaro Prieto, Teófilo Cid and Arturo Méndez Carrasco's chronicles, who write from theirs positions as employees, portray writing just as a main skill to accomplish their work and it is not always linked to literature and/or journalism.
\end{abstract}

Keywords: writting, Chilean chronicle, journalism, chroniclers, employees.

Recibido: 29-12-2015

Aceptado: 21-01-2016

* Este trabajo da cuenta de ideas en progreso que también están siendo aplicadas en un corpus más extenso que incluye a cronistas latinoamericanos en el marco del proyecto Fondecyt Iniciación $\mathrm{N}^{\mathrm{o}}$ 11140881, dedicado a la crónica latinoamericana del siglo XX, del cual la autora es la investigadora responsable. Partes de este análisis también derivan del trabajo realizado en el marco del proyecto Fondecyt Regular $N^{\circ} 1150141$, enfocado en imaginarios de la lectura en la narrativa chilena entre 1940 y 1960, del cual la autora es co-investigadora. Agradezco a mis colegas del CIDOC (Universidad Finis Terrae) por la lectura y comentarios a este texto.

** Chilena, PhD., University of California, Davis. Directora del Centro de Investigación y Documentación (CIDOC) de la Facultad de Comunicaciones y Humanidades de la Universidad Finis Terrae, Santiago, Chile. cdarrigrandi@uft.cl 
Reconocida, junto con la lectura, como una herramienta elemental para conseguir un trabajo de empleado en las sociedades modernas, sobre todo a partir de mediados del siglo XX, la práctica de la escritura pareciera, a veces, pasar desapercibida, en particular cuando se aleja de lo que se ha entendido como escritura literaria. A modo de repensarla en un género que en sí mismo la problematiza por su hibridez, este artículo se enfoca en el acto de la escritura desde el punto de vista más material, como lo es el hecho mismo de sentarse a escribir como también desde las motivaciones, obligaciones y deseos que lo anteceden. Para esto, se analizará un corpus de crónicas publicadas en la prensa chilena desde la primera mitad del siglo XX hasta mediados del mismo. Más que profundizar en la propuesta de cada uno de estos cronistas, el foco del artículo está puesto en los lazos que se pueden establecer en un panorama de representaciones de la escritura vinculado a la construcción del imaginario del acto de escribir y quien lo realiza, en este caso, representado por el cronista. Algunos de éstos son, además, empleados cuya relación con la escritura, muchas veces, es un requerimiento y una función elemental para poder desempeñarse en su trabajo. En consecuencia, esto permite presentar una reflexión sobre el acto de escribir en contextos laborales en diálogo con otros imaginarios de la escritura que circulan, sobre todo con aquellos vinculados a la noción de escritor "literario", de novelista o poeta, o del que aspira ser escritor profesional. Hernán Díaz Arrieta (Alone), en diversos medios de prensa, y Joaquín Edwards Bello, principalmente en La Nación, responden en sus crónicas a un público lector que demanda consejos para lograr una buena escritura o para llegar a ser escritor, figura que, según se desprende de las crónicas, se erigía con un aura especial ${ }^{1}$. Alone escribe desde lo que en esa época se entendía como crítica literaria y, en ese contexto, la vida del autor cobraba una importancia fundamental al momento de criticar o reseñar un texto ${ }^{2}$. Edwards Bello, por su parte, oscila entre la figura del periodista y el cronista ya consagrado. Por otro lado, Jenaro Prieto, Teófilo Cid y Arturo Méndez Carrasco escriben, por decirlo de alguna manera, desde el "lado B" de la escritura, un lugar menos idealizado donde no se dan lecciones a los eventuales futuros escritores. Escriben de

1 Para las crónicas de Hernán Díaz Arrieta se ha consultado el libro Alone. El vicio impune (50 años de crónicas) (1997) y para el caso de Joaquín Edwards Bello se ha recurrido a la antología En torno al periodismo y otros asuntos (1969). Ambas antologías fueron preparadas por Alfonso Calderón.

2 Conviene recordar la influencia que Charles Augustin Sainte-Beuve ejerció en su labor de crítico literario. 
su trabajo como cronistas o empleados y desde un lugar que, al mismo tiempo, les permite pronunciarse tanto de literatura como también sobre muchísimos asuntos del día a día laboral.

Las crónicas de Jenaro Prieto (1879-1946) fueron publicadas desde 1915 hasta 1946 en El Diario Ilustrado; muchas de las escritas por Teófilo Cid (1914-1964) se publicaron en la década de los cincuenta en el diario La Nación $n^{3}$ y, por último, las crónicas autobiográficas de Armando Méndez Carrasco (1915-1984) aparecieron en la década de los sesenta en Las Últimas Noticias bajo el seudónimo de Juan Firula ${ }^{4}$ Estos tres escritores, además de ser periodistas, jefes de redacción y cronistas, desempeñaron cargos públicos de distinta índole. Prieto fue electo diputado por el Partido Conservador el año 1932, Cid ocupó un cargo en el Ministerio de Relaciones Exteriores en el mismo decenio y Méndez Carrasco, por su parte, perteneció a Carabineros de Chile por 10 años, además de ser empleado del Ministerio de Educación y del Ministerio de Obras Públicas. Si ser empleado público o empleado a secas les permitía ubicarse en algunas de las zonas de la escurridiza clase media y los diferenciaba de los obreros (aunque en muchas crónicas estos escritores intentan asimilar su trabajo al de un "obrero de las letras") y de las élites económicas -en tanto su trabajo se asociaba con la producción intelectual-, como burócratas $u$ oficinistas conocieron de cerca el tedio y el despropósito de la escritura: "no pueden imaginarse la tragedia de pasar días y días sentado frente a una mesa transcribiendo oficios para que otro los copie y los transcriba" señala Prieto en su crónica "La voz olvidada" (122-123). Por su parte, Alone dedicó gran parte de su trabajo periodístico a la crítica literaria y Joaquín Edwards Bello abordó un sinnúmero de tópicos. Sin embargo, para los propósitos aquí señalados, recogemos algunas crónicas en las que se dirige a los lectores que se le presentan como aspirantes a escritores.

De este modo, en las siguientes páginas se propone fijar el lente en la relación con la escritura de sujetos heterogéneos que intentan inscribirse tanto en el campo literario como en el periodístico sin negar

3 Teófilo Cid también publicó en La Hora y en Proarte.

4 El corpus de crónicas de estos autores proviene de los libros Pluma en ristre (1925), Con Sordina (1930) y Humo de pipa (1955), para el caso de Jenaro Prieto; Crónicas de Juan Firula (1965) para el de Arturo Méndez Carrasco; y, para las de Teófilo Cid, fueron consultadas directamente en el diario $\mathrm{La}$ Nación donde publicó en la década del cincuenta. Es necesario señalar que algunas de sus crónicas fueron publicadas en Hasta Mapocho no más (1976), una antología editada por Alfonso Calderón. 
que, dentro de sus múltiples funciones y trabajos desempeñados para lograr el sustento económico más que la satisfacción profesional, también son empleados y, en algunos casos, sus funciones son las propias de los funcionarios públicos. Dicho de otra forma, ¿Cómo se incorpora en la práctica de la crónica el acto de la escritura? ¿En qué medida la emergencia de la figura del empleado y de empleado público se imbrica con la figura del cronista/ periodista e interviene en la manera de abordar la escritura? La crónica periodístico-literaria es un espacio adecuado para problematizar esa delimitación de los saberes en tanto que el género crónica mismo los complejiza, pero también sus propios productores son figuras múltiples que no se adscriben a un solo campo profesional. Antes de 1925, comentando la adscripción de nuevos miembros a la Academia Chilena, entre ellos Carlos Silva Vildósola, Jenaro Prieto destaca, primero, la escritura como una herramienta compartida entre muchas profesiones; segundo, la escasez de escritores: "Porque una de las características más comunes a nuestros 'inmortales', es la de no ser literatos. Entre ellos hay políticos, funcionarios públicos, historiadores, coleccionistas de dichos populares, abogados, etc., pero los escritores brillan, en general, por su ausencia" ("Académicos" 51-52).

De ningún modo este trabajo pretende ser exhaustivo, sino que intenta capturar ideas en circulación que en las crónicas no se presentan con un desarrollo argumental acabado en tanto que suelen ser textos relativamente breves donde se señala la espontaneidad o la "reflexión en progreso". Así como Aníbal González y Susana Rotker plantearon la escritura de la crónica modernista como una "escritura bajo presión", en este trabajo se plantea que las crónicas surgen a partir de un acontecimiento o de alguna anécdota vinculada a la cotidianidad, y el cronista enfatiza ese suceso, ese presente o ese momento como el que da paso a la escritura. O bien, la crónica es la anécdota en sí misma. Es decir, que el énfasis en la espontaneidad o la relación del desarrollo de una idea con lo anecdótico se podrían entender, eventualmente, como una estética de la crónica. Es en ese sentido que planteamos su contenido como reflexiones en progreso en tanto que el asunto abordado se presenta en un contexto de fugacidad y, de este modo, no se termina de comentar (o pensar) en una sola crónica y vuelve a cobrar un lugar relevante en otras crónicas. Es por ese motivo que en las páginas que siguen se toman conjuntos de crónicas para que, de este modo, se pueda, más o menos, 
articular un mapa de lo que plantean sobre la escritura. Asimismo, no siempre existe coherencia entre las ideas vertidas entre una crónica y otra. Como plantea Enrique Espinoza (Samuel Glusberg), director por muchos años de la revista Babel, en el ensayo que abre su libro De un lado y otro (s/f): “Una idea determinada logra distinto desarrollo en el diario, la revista o el libro. Por lo general, halla en el primero su forma incipiente; otra, menos efímera en la segunda; y solo en el último, su posible plenitud" ("El diario, la revista, el libro" 9). En este sentido, esa escritura bajo presión no necesariamente es un defecto, sino que puede ser reveladora de "ideas", "percepciones" o "imaginarios" que se propagan en conversaciones de pasillo, en cafés, en las oficinas (de redacción), tertulias, etc. Se arguye entonces que estas ideas o reflexiones, que no siempre llegan a ser parte de textos con argumentos plenamente desarrollados, informan las escrituras periodísticas y, muchas veces, estos pensamientos pueden también estar vinculados al ejercicio de la profesión o a la productividad del empleado. En consecuencia, en este análisis de la crónica periodístico-literaria chilena, se entiende la prensa como un espacio relevante para la circulación de imaginarios y opiniones sobre la escritura, oficios que dependen de ella y sobre la literatura que, a su vez, es parte de los debates que contribuyen a la construcción del campo literario y cultural. En ese sentido, estamos considerando la crónica como una práctica y, como tal, interesan no solo sus atributos discursivos sino también otros gestos y acciones que circundan o participan de la escritura que, a su vez, se filtran en su factura ${ }^{5}$.

"A mí me pagan, pues, por suicidarme y lo hago valientemente y a conciencia", señala Jenaro Prieto en su crónica "Humo de pipa..." $(9)^{6}$. En esta crónica, Prieto alude a una reiterada crítica que se le hace al periodismo quienes desean, en el fondo, ejercer otra profesión de poca o ninguna retribución económica: ser un oficio del cual se obtiene el necesario ingreso económico y que, a su vez, no garantiza ninguna

5 Junto con los clásicos estudios de Aníbal González, Julio Ramos y Susana Rotker acerca de la crónica modernista, para un análisis de la crónica como práctica sugiero consultar el libro de Viviane Mahieux, Urban Chroniclers in Modern Latin America (2011). En ese estudio se plantea cómo la crónica se construye también a través de su lectura, entre otras condiciones. En cuanto a la crónica como género discursivo, recomiendo revisar el libro de María Josefina Barajas, Textos con salvoconducto: la crónica periodístico-literaria venezolana de finales de siglo XX (2013), quien profundiza y problematiza todavía más la hibridez que caracteriza el género al incorporar en la discusión la relación entre la crónica y las ciencias sociales.

6 Desconozco la fecha exacta de la publicación de esta crónica, pero aparece publicada por primera vez en Con sordina el año 1930, de la editorial Nascimento. 
satisfacción profesional. Y si bien el cronista de El Diario Ilustrado no descarta que otros trabajos también terminan con la vida de las personas, en tanto "el cansancio" es una "intoxicación", destaca de este texto no solo la posibilidad de muerte, no solo la inexistente satisfacción profesional, sino también el reconocimiento de la inutilidad del propio oficio. No sin ironía, Prieto se encarga de señalar que su escritura periodística no existiría si no fuera por la pipa, "[e]n el fondo de cada pipa, hay un artículo" (9). El humo de pipa hace funcionar al cronista que, en este caso, es también una máquina o una fábrica que echa humo, sintonizando, de este modo, su escritura con los procesos de producción industrializados y el mundo obrero. En las primeras páginas de El libro tachado (2014), Patricio Pron se detiene en algunos personajes que aspiraron a crear máquinas autómatas o métodos de hacer literatura sin la intervención del autor, lo que en algún momento llama "literatura mecánica" (12). Rescato esas reflexiones iniciales que hace el crítico argentino porque, en el caso de Prieto, la idea de la máquina no reemplaza ni hace desaparecer al autor sino que, en cambio, lo potencia: "la pequeña dosis de vida que pierde el operario al extraer, a fuerza de chupadas, esa sustancia inmaterial que fluye del tabaco $y$, después de algunas vueltas por el alambique del cerebro, logra fijar en el papel, mediante un poco de tinta" ("Humo de pipa..." 9). Se deviene máquina para poder escribir, aunque no se plantee explícitamente que esa escritura sea literatura, sí se presenta como una que pertenece al mundo de las ideas. La ironía de Prieto continúa y se extiende

Los hombres de ciencia no lo saben, porque el análisis químico, grosero y materialista, no alcanza a aislar las ideas. No aparecen en el tabaco, ni en la nicotina, ni en el humo. El artículo viene a ser un subproducto que los químicos desprecian por inútil. Yo también creo que es inútil; pero he encontrado la manera de venderlo [...]. ("Humo de pipa..." 9)

La cita anterior pone en el centro el resultado del acto de escribir como el principal problema. Esas escrituras poco definidas como la crónica o el artículo -propias de un periodismo-, y en particular durante el periodo que escribe Prieto, donde no estaban formalizadas ni institucionalizadas en escuelas y programas de estudios, y cuyos autores oscilan entre el periodismo, la literatura y otros oficios, carecen de utilidad alguna en un mundo donde las ciencias comienzan a cobrar un lugar cada vez más relevante como garantía de verdad y productividad. No obstante, este 
hombre máquina parte de un sistema productivo y encuentra su sello personal. "[H]e encontrado la manera de venderlo", señala el cronista, de modo que la singularidad de la voz autorial no está amenazada por la maquinización del cronista. Al mismo tiempo, logra definir su sello distintivo, cualidad destacada por los críticos especializados sobre los cronistas.

De la inutilidad destacada e ironizada por Prieto, un par de décadas después, cuando el campo literario y el periodístico estaban más definidos, Teófilo Cid señala otro problema que, al mismo tiempo, inscribe y se pregunta por la función del escritor en un sistema de producción. El autor, en "Nadie sabe para quién escribe...", publicada en el diario $L a$ Nación el 2 de mayo de 1958 señala: "Si escribimos con la idea de que se nos lea, con el propósito de que se nos atienda, estamos preocupados, tal el músico moderno, más del problema de la temperación del instrumento que del contenido mismo. [...]. La mecánica, en este caso, la prensa, nos está demarcando y nos está obligando" (4).

Sin duda, la inquietud expresada por Cid sobre las obligaciones o requisitos que se le imponen a la escritura desde algunos registros y formatos como el periódico, y la necesidad de forjar una lectoría, no era nueva en el contexto chileno de mediados de siglo. A primera vista, pareciera que a Cid no le preocupa que lean sus colaboraciones semanales en La Nación y expresa un pequeño malestar por tener que ocuparse de que éstas sean, efectivamente, leídas. A pesar de que algunas líneas antes del fragmento citado Cid reconoce que evidentemente se escribe para alguien aunque no se sepa quién -“nadie escribe para sí mismo"-, la prensa impone una forma y deja en entredicho que la escritura que se desea lograr sea del interés de los lectores. En ese sentido, tanto Prieto como Cid postulan la inutilidad de su escritura en tanto se circunscribe en espacios donde los beneficios o la función de su producción no está en cuestionamiento; en este caso, en palabras de Prieto, serían las "empresas periodísticas ("Humo de pipa" 9).

En el mismo espacio de la prensa, en periódicos y revistas, a mediados de siglo XX Alone publicó una serie de crónicas en las que vehicula sus comentarios, opiniones, impresiones sobre la "escritura literaria". Al año siguiente que se publicara "Nadie sabe para quién escribe" de Cid, en el mismo periódico Alone publica "La carrera literaria" y expresa inquietudes similares a las de Cid pero, a diferencia de este último, se 
enfoca específicamente en la literatura. Al crítico le preocupa el papel de los medios de comunicación alternativos a la prensa escrita en la definición de la literatura:

Para medir el nivel de lo que el gran público entiende por literatura, de lo que lee y que busca y, en consecuencia, paga, más que la boga de los libros, necesariamente reducidos, sirven los programas de radio, cada vez más difundidos y que entre sus aficionados cuentan a esa, no la olvidemos, enorme masa excluida de las letras, los proscritos de la cultura, al margen de la civilización, especies de parias, entre los cuales vivimos tranquilamente, sin advertirlos casi: los analfabetos.

En las audiciones radiales son ellos los que dictan la ley, arreglan el programa, disponen los números e imponen, incluso, la forma y el tono en que se desarrollarán. [...] De palabra en palabra y de explicación en explicación, llegóse al siguiente aforismo: audición que no sintonizan, es decir, que no escuchan las cocineras, que no les gusta, es audición muerta. $(242-243)^{7}$

Alone traslada el problema a las audiencias y, para hablar de literatura, deja los libros y se desplaza hacia el mundo de la radio. Esta operación, más que resolver lo que se entiende por literatura, enfatiza la popularidad de otros medios de comunicación, gesto que le permite insistir en la lectura como una práctica selecta. Por último, lo que hace Alone es reafirmar su lugar como crítico especializado, a diferencia de una masa que no nos puede informar de literatura porque, sencillamente, no lee.

Retomando a lo planteado por Cid, convendría señalar que su crónica se inicia con una alerta hacia la nueva tecnología: "El que no ha estado frente a un micrófono, sabe poco de lo que es el terror sagrado" ("Nadie sabe para quién..." 4) $)^{8}$. El temor al micrófono se debe a que acentúa

7 Para el caso de Alone, aunque se mencionen las fechas originales de publicación, las citas han sido tomadas del libro Alone. El vicio impune (50 años de crónicas). Santiago: RIL editores, 1997.

8 Es interesante la relación de los escritores con la tecnología. Ese tópico es bastante trabajado por Susana Rotker y Julio Ramos para el caso de la crónica modernista. Viviane Mahieux también se hace cargo de esa relación para el caso de las décadas de los 20 y 30; no obstante, para el corpus que ella estudia se plantea que la relación con la tecnología es mucho más fluida y los cronistas como Alfonsina Storni, Cube Bonifant, Roberto Arlt, Salvador Novo y Mario de Andrade, no necesariamente sienten su trabajo amenazado por ella. 
todo lo dicho y, lo que es peor, lo mal dicho, porque es un "difamador de nuestros defectos de pronunciación" (4). Es por eso que, como se mencionó anteriormente, el cronista hace un llamado a poner atención al contenido que, para el caso de la prensa, se vincula con la información, la noticia y, también, la opinión. Pero la crónica de Cid no ahonda en ese asunto, porque, finalmente, lo importante es la incógnita en cuanto a la identidad de sus lectores y la soledad del cronista:

Entre la soledad de la oficina en que ahora me encuentro escribiendo, entre este silencio apenas amagado por el ruido de la Underwood, y el bullicio de la ciudad, los problemas de los otros hombres o mujeres que mañana comprarán el diario, se levanta un tabique realmente monstruoso. ¿Qué ojos pasarán por las delgadas líneas y penetrarán, a través de las signaciones fonéticas, para meter la inquisitiva mirada espiritual en lo que estoy escribiendo? ("Nadie sabe para quién..." 4)

Hay una conciencia sobre la lectura que intriga la escritura del periodista. Esta declaración pareciera informar del fracaso del Cid cronista quien, a diferencia de Prieto, no mantiene un diálogo constante y explícito con el ciudadano común que circula por el Santiago de la década del cincuenta. Sus escritos, publicados en la sección editorial, comparten la página con la columna editorial, las cartas al director, "Las notas del día", entre diversas columnas de opinión escritas por otros escritores y periodistas. Y, entre ellos, también está el cronista Joaquín Edwards Bello, quien rápidamente, con su humor ácido e irónico, estableció vínculos con una comunidad lectora que dio sustento a cuarenta años de producción periodística que se traducen en aproximadamente 12 mil crónicas ("Los jueves"). Difícilmente Cid podía competir con "Los jueves de Joaquín Edwards Bello" quien en "A un cronista" señala que: "El éxito de un cronista de diario depende de la simpatía que irradian sus escritos. La simpatía es comprensión. Se desarrolla cuando el lector descubre que han expresado sus propias ideas o deseos, con gracias y claridad" (93).

En las crónicas de Alone, muchas de ellas recopiladas por Alfonso Calderón en el libro Alone. El vicio impune (1997), se plantea que la buena escritura solo parece lograrse por quienes poseen el don: no hay recetas ni técnicas claras para llegar a ser un buen escritor. Sin embargo, Alone coincide con Cid al señalar que "una de las formas de escribir mal es 'no 
tener nada qué decir'. Lo antepongo a todo, porque me parece el más seguro" (Alone, "Distintas maneras" 129). Para ser más precisos, en la crónica "Distintas maneras de escribir mal", publicada originalmente el año 1946 en la revista Zig-Zag, Alone no indica exactamente que existan "formas" de escribir mal, si no que hay "sistemas". Retomando las ideas sobre la especialización, profesionalización y la presencia de las ciencias en el mundo de la productividad, la palabra "sistema" se inscribe en el campo semántico de lo que se asocia con la técnica y con cuestiones de método y metodología9. Por lo tanto, Alone se apropia de un lenguaje científico para hablar de la escritura literaria, lo que le permite, al menos simbólicamente, "profesionalizar" la literatura y signar su propia profesión de crítico literario al tiempo que, también, su crónica se diferencia de un escritura "literaria". Las crónicas de Alone corresponden a la escritura del crítico y no del "escritor" y, en este sentido, su trabajo se adscribe a una especialidad que, paradójicamente, no es fácilmente identificable en el caso del escritor (profesional).

La crítica de Cid, como también la de Alone, son parte de una reflexión sobre los avances tecnológicos aplicados a la entretención y a los medios de comunicación masivos: "En realidad, ese poder demoníaco tiene los artefactos mecánicos con que actualmente la humanidad memoriza la palabra, el sonido, la imagen o la música” ("Nadie sabe para quién escribe..." 4). En cierta medida, Cid teme, y no celebra, la mecanización de la escritura, pues acentúa los defectos y limita el trabajo creativo. Asociada con la práctica del registro, la crónica latinoamericana es también un registro de su propia factura, es decir, de su propia escritura. En su libro Texto con salvoconducto: la crónica periodístico-literaria de finales del siglo XX (2013), María Josefina Barajas señala como una de las señas distintivas de la crónica la "insistencia [del narrador] en mostrar vínculos de identidad con el relato escrito: al llamar la atención respecto a su trabajo narrativo, o, bien, al hacer notar su grado de afinidad con la historia narrada" (149). Este género, desde sus antecedentes coloniales, tiene como rasgos característicos dar cuenta de acontecimientos relativamente inmediatos $\mathrm{y}$, a su vez, contiene como una de sus características principales incluir el

9 A mediados del siglo XX, Chile comienza un proceso de industrialización al igual que en muchos países de Latinoamérica, adquiriendo gran fuerza durante los gobiernos del Frente Popular. En este sentido, sería interesante profundizar en cómo el discurso de la industrialización y de la productividad se filtra en la escritura de las humanidades, como también en la inclusión de la información que es producto de estos discursos. 
ejercicio mismo de la escritura en la textualidad de la crónica ${ }^{10}$. Aunque parezca una obviedad, pues todo cronista que publique en prensa tiene una deuda impostergable con su presente y su entorno para que su escritura tenga un sentido, quien escribe crónica del día a día deja filtrar, de forma explícita, rasgos de esa atmósfera, espacio y lugar.

En una crónica intitulada "Por qué escribo" del 27 de octubre de 1954, Cid señala:

En el mundo latino, los escritores no tenemos nada que hacer. Nos pagan mal, nos acusan de comunistas y nos molestan. Yo estoy acostumbrado a eso. Como no represento a nadie y como, además, pertenezco a un mundo espiritual sin estructura, a esta desgraciada clase media chilena que todos ustedes conocen, cada vez que firmo un artículo hay por lo menos cien que protestan. (4)

Es interesante destacar esa forma que Cid tiene de referirse a la clase media ("mundo espiritual sin estructura") pues revela la dificultad representacional, que la historiadora Azun Candina también señala, de la clase media en Chile. De este modo, se reafirma en las crónicas de Cid que el cronista no tiene claridad sobre sus lectores o, si acaso podría ser posible, que estuviera representand o los intereses de alguien o a un grupo, convirtiéndolo, por lo tanto, en tanto letrado que reflexiona y crítica el acontecer de su sociedad, en un intelectual orgánico, en términos de Gramsci. De todos modos, al poner en duda esa posibilidad, Cid destaca nuevamente la soledad de su oficio. Por su parte, Joaquín Edwards Bello reclama por la ignorancia que hay sobre el oficio de periodista:

Cada cual tiene sus preocupaciones personales, sus manías, pero cada cual suele olvidar que el periodista también las tiene, y no por ser periodista, ha de atender en el día a cuatro o cinco personas que se creen poseedoras del derecho para

10 Esta reflexión sobre la propia escritura, en el contexto de la crónica periodístico-literaria, revela diversas preocupaciones, y es muy evidente en el caso de algunos cronistas. Por un lado, la inquietud puede darse desde el punto de vista del relato que se está elaborando o el estilo utilizado; por otro lado, puede remitir la práctica misma de la escritura. Por mencionar un par de ejemplos, ya es clásica la crónica de Roberto Arlt “¿Cómo quieren que les escriba?” (3 de septiembre de 1929) en la que responde a una serie de reclamos por el uso del lunfardo en el espacio de su crónica. Véase Obras completas. Tomo 2. En otro contexto, es también muy interesante el caso de las crónicas que Clarice Lispector publicó a finales de los sesenta e inicios de los setenta en el Jornal do Brasil. Lispector informa al lector de las pausas y de las actividades paralelas que desempeña mientras está escribiendo la crónica que el lector tiene en sus manos en ese momento. Véase Revelación de un mundo. 
ser partícipes a las otras de sus entusiasmos, sus manías, sus pasiones y dificultades. ("No embrollemos la vida" 4)

Del comentario de Edwards Bello se desprende que el oficio del periodista tiene una relación directa con la audiencia y ésta, a su vez, ve en él un servidor a quien se le puede interrumpir según se estime conveniente. A diferencia de la soledad de Cid, las crónicas de Edwards Bello son mucho más dialógicas.

En el mismo espacio de la prensa, mientras cronistas de la vida cotidiana dejaban filtrar, a veces, sus inquietudes con la escritura como práctica, desde la crónica literaria, desde la especialidad del oficio de la crítica literaria, Alone daba sus consejos, evaluaba y jerarquizaba el universo literario nacional e internacional. Muchas de las crónicas de Alone compiladas en la antología ya citada se enfocan en dar respuestas a jóvenes que piden consejos para ser buenos escritores o las condiciones, capacidades y habilidades que se deben desarrollar para lograr ser un escritor. Sus respuestas, por momentos, dan cuenta de una visión romantizada de la escritura -que también es visible en la crónica de Arturo Méndez Carrasco-, porque como señala en su crónica "Matar su alma", no escribir es "abstenerse de la vida superior" ("Matar su alma" 65-66). Sin embargo, hay un reconocimiento tácito de que la escritura tiene una metodología, aunque al momento de precisar los consejos para lograr una buena escritura el crítico no puede identificar el procedimiento adecuado: "En resumen, elija cada cuál su método. Para ello, estúdiese, analícese, conózcase y descubra qué sistema de cultivo le conviene, como a las tierras. Escribir bien es solo hallar la relación entre lo que se quiere y lo que se puede" ("Trabajar el estilo" 46). Apelando a un sistema inductivo, Alone sitúa la escritura dentro de una ciencia, pero luego señala, en otra de sus crónicas, que el éxito para quien quiera ser escritor, a pesar de su materialidad y de su práctica, no responde a regla alguna: "Es que no hay regla fija" dice después de que ha repasado sucintamente los contextos espaciales del acto dela escritura de Valéry, Dublé Urrutia, Balzac, Zola" ("El misterio de escribir" 37). $\mathrm{Y}$ ante la posibilidad de concretar una respuesta, concluye diciendo: "En suma, del misterio de escribir puede afirmarse todo. Igual que del amor" ("El misterio de escribir" 38). En este contexto, parece interesante el esfuerzo por racionalizar una actividad que intenta profesionalizarse pero que al mismo tiempo sigue generando una tensión con las reglas 
que el proceso impone. Concluye Alone que no hay método para ser escritor; no obstante, es un conocimiento altamente deseado y preciado. Por su parte Cid, en su crónica ya citada "Por qué escribo", señala este problema, pero desde otro punto de vista:

Siempre me he quedado pensando por qué escribo. Para escribir no existe ninguna necesidad de ir a la universidad ni de frecuentar los conservatorios. La profesión de escritor es la profesión más libre que hay en el mundo. Jamás podría alguien siquiera imaginar que un poeta vaya a una academia a aprender a escribir sonetos, pongo por caso. Yo, al menos, aprendí a escribir sonetos cuando tenía doce años y me costó muchos dolores de cabeza el darme cuenta de que un soneto perfecto debe estar compuesto en versos iguales. (4)

A partir de esta cita se podría señalar que a mediados del siglo $X X$ la escritura, al forjarse una identidad de escritor, tensiona los atributos que componen lo que se considera profesional como lo serían las metodologías, procedimientos y quehaceres propios de cada área. Aunque de todos modos, la misma crónica de Cid revela que hay una información que tuvo que descubrir autodidactamente. En este sentido, el espacio de la crónicas, según el corpus aquí seleccionado, da cuenta de esas tensiones, al mismo tiempo que es un canal a través del cual se vehicula el problema. La crónica periodístico-literaria es un género hibrido cuyo "método" puede diluirse aún más que en otras escrituras, pero es también una plataforma donde se expresan opiniones, subjetividades, consejos y comentarios sobre la metodología o los recursos a los que se debe recurrir para ser un escritor. "En el Día del Trabajo es bueno, para un hombre acostumbrado al ocio de las letras, meditar sobre el trabajo, esta actividad voluntaria y consciente del hombre que a tantas consideraciones se ha prestado", así comienza su crónica "Ocio y trabajo", Teófilo Cid, el primero de mayo de 1955. Al señalar que es un "hombre acostumbrado al ocio de las letras", el cronista ironiza lo que su figura como poeta del grupo Mandrágora representaba ${ }^{11}$. Y, de este modo, aunque está cargado de ironía, pareciera que desmantelara todos aquellos esfuerzos que se fraguan en otras crónicas, columnas y periódicos que intentaban sistematizar el oficio del escritor. Retomando esta figura ociosa que Cid 
intenta destacar en oposición a la escritura como parte del trabajo, Luis de Paola asocia al poeta chileno con Charles Baudelaire, ícono de la bohemia parisina del siglo XIX. El periodista indica que Cid era una "leyenda viva" y, más interesante para el propósito de este artículo, sentencia que "No había nacido para un destino tan pequeño como ser un funcionario remunerado" (18). Sin embargo, esta idea del escritor ocioso que hace referencia al "master de la noche", como era conocido entre la bohemia chilena, está muy lejos de la imagen de cronista que construye en La Nación (La Nación 1/5/1955 4). Entre comentarios de actualidad, tanto de la vida cotidiana como de la literaria, Cid dedica unas pocas crónicas para reflexionar sobre el acto de la escritura. En este contexto, protege su especialidad en tanto cronista y revela una preocupación por la utilidad del oficio del escritor, en el amplio sentido de la palabra, que poco tiene que ver con la escritura como actividad ociosa. Un mes después de su crónica inspirada por el Día del Trabajo, el 1 de junio de 1955, en "La 'desvirtuación' profesional", ante la moda de convertirse en escritor, ante la facilidad con algunos deciden escribir, Cid señala: "Es muy seguro que este hombre se preguntó: ¿por qué si Neruda escribe, yo no puedo hacerlo? Cuando un ser humano cualquiera que sea su ilustración, se hace esa pregunta, escribe". Y luego continúa: “QQué dirían ustedes si a mí, especializado en San Juan de la Cruz y en Paul Eluard me diera el berretín de botarme a médico?" (4). De un asunto similar ya se estaba ocupando Alone diez años antes. En su crónica "La tentación literaria", publicada originalmente en la Revista de la Sociedad de Escritores de Chile el año 1945, el crítico, junto con plantear el problema, evidencia también una de las debilidades del campo literario:

[U]n joven que desea en Chile dedicarse al conocimiento de las letras y 'aprender a escribir' se halla desprovisto de medios para orientarse.

Porque los pintores tienen la Escuela de Bellas Artes, con sus maestros y exposiciones, y los músicos el Conservatorio y los conciertos; pero el futuro escritor, el futuro poeta, por mucho que busquen, no encuentran dónde reclinar su cabeza. (“La tentación literaria" 111)

11 En una revisión de la crítica de prensa al trabajo y figura de Teófilo Cid, es notorio el rescate que se hace de la figura del poeta en contraste con la de periodista o cronista. 
Al momento de publicarse estas crónicas, pareciera que la institucionalidad literaria es mucho más precaria e imprecisa que la de otras profesiones ${ }^{12}$. En ese contexto, diez años después, la crónica "La 'desvirtuación' profesional" de Cid revela un intento por dar cuerpo a esa actividad cuyo ejercicio es entendida como un derecho de todos. En ese sentido, cuando Cid reclama por las atribuciones que se toman otros para escribir literatura sin ser escritores y, al mismo tiempo, muestra cierto inconformismo por no saber para quién escribe, deja abierta la interrogante de si se siente inútil o privilegiado. Inútil como Prieto que escriben, a veces, por obligación. Privilegiados porque al menos Cid tiene la autoridad para escribir literatura y sobre literatura. Del mismo modo, al burlarse de la persona que quiere escribir, Cid delimita su campo y enfatiza el carácter productivo de su oficio contrarrestando el estereotipo del escritor bohemio. Por su parte, Joaquín Edwards Bello en su crónica "Consejos al joven que desearía ser escritor" señala:

Son muchos losjóvenes-varones y mujeres-, que nos escriben de provincias, con ensayos adjuntos, preguntándonos en qué condiciones podrían ser admitidos en la prensa o en las editoriales de esta capital. Desean ser escritores [...].

En mi ser interior, y con la más desnuda sinceridad, yo les deseo el fracaso en sus primeras obras para que así no se vean arrastrados al opio de escribir. (47)

La palabras de Edwards Bello insinúan también la moda de "ser escritor", de ser parte del entramado editorial y el eventual endiosamiento que ha adquirido la figura del intelectual o del hombre público que se dedica a las letras. La escritura deviene en un alucinógeno que seduce y, peor aún, la audiencia no puede distinguir entre tanto escritor: "Lo difícil es que en el público se forme la conciencia de cuáles son estos glosadores y guías auténticos. Abunda el pirata, el simulador, en la política y en el pensamiento escrito" (47). "Además, es un oficio que saca pica", señala Edwards Bello en su crónica "Odio al escritor" (53). No deja de ser interesante que tanto Edwards Bello como Cid demarquen su territorio, porque en la década de los cincuenta la especificidad de la disciplinas ya estaba consolidada. Por eso la idea de que el ser escritor

12 Para la los cambios en el campo literario chileno durante el periodo comprendido entre finales del siglo XIX e inicio del XX, véase Catalán. 
cobra fuerza como moda debería ser explorada en mayor profundidad ${ }^{13}$. Para mediados de siglo XX, por un lado con la creación de facultades, escuelas y cátedras en el contexto universitario y, por otro, gracias a las asociaciones, colegios y otras agrupaciones gremiales, además de la publicación de revistas especializadas con la proliferación de secciones dedicadas a las letras o a la cultura y los suplementos culturales de la prensa, el campo literario estaba definido. El reclamo de Cid cobra fuerza, a diferencia del periodo modernista cuando, hasta cierto punto, todo aquel podía ensayar ser escritor y para eso el periódico era uno de los mejores soportes, a mediados del siglo XX chileno el ejercicio de la escritura tiene su especificidad y existe una institucionalidad que dota a Cid de la autoridad necesaria para hacer ese reclamo.

En el libro Por una vida digna y decorosa. Clase media y empleados públicos en el siglo XX chileno (2009), Azun Candina señala que los empleados públicos y particulares comenzaron a organizarse en la década del veinte $y$, ya a partir de los años treinta y cuarenta, "florecieron las agrupaciones de empleados y funcionarios de 'cuello' y 'corbata' fiscales y semifiscales" (Por una vida digna 51). Asimismo, sitúa a la figura del empleado público como una de las muestras más representativas de la clase media chilena, la que, no obstante, se va a distinguir de los grupos sociales más altos y más bajos de la jerarquía social por ser el resultado de las campañas alfabetizadoras y educacionales de las primeras décadas del siglo XX. De este modo, el dominio de la escritura, la lectura y las profesiones accesibles a ellas gracias a esas capacidades pasan a ocupar un lugar central en la identidad laboral. Este punto es interesante porque estas agrupaciones que denotan una colectividad que se identifica por un quehacer, dan cuenta de nuevos sujetos urbanos asociados a un tipo de productividad que es causa y consecuencia del crecimiento del Estado ${ }^{14}$. Por otra parte,

13 Por mencionar algunos ejemplos concretos, entre 1931 y 1932 se funda la Sociedad de Escritores de Chile y dentro de sus objetivos estaba la profesionalización del oficio del escritor, conseguir el apoyo del Estado para la creación de concursos y premios -como el Municipal-, la realización de ferias, entre otras acciones orientadas a generar una institucionalidad para la literatura (Aguilera y Antivilo). En 1953 se crea la Escuela de Periodismo de la Universidad de Chile y tres años después nace el Colegio de Periodistas. Para otros detalles de las transformaciones del campo literario chileno de inicios del siglo $\mathrm{XX}$, véase Catalán.

14 En Clase media, Estado y sacrificio, Candina plantea que según los registros de las cuentas nacionales de la CORFO, "para el periodo 1940-1950, es posible ratificar que efectivamente hubo un crecimiento significativo de los empleados y obreros en los llamados 'servicios gubernativos', que aumentaron casi al doble en un período de catorce años" (43). Si en 1940 se contabilizaron 83.546 empleados y 35.232 obreros en "servicios gubernativos", para el año 1954 se contaron 130.637 empleados y 78.926 obreros (43-44-) 
también se asocian a un método de trabajo que se distingue de otros y que muchas veces demandaba el dominio de la escritura, idealmente a máquina, como tecnología elemental para poder conseguir un trabajo como empleado. Según el historiador Jorge Rojas, fue en el año 1924 cuando "la legislación laboral [...] marcó una distancia entre obreros y empleados, diferenciando entre quienes se dedicaban al trabajo manual (obreros) y al intelectual (empleados), señalando que debían formar agrupaciones separadas y con diferentes características" (ctdo. por Candina, Por una vida digna 50). Sin embargo, aquí quisiera enfatizar que a esa distinción debe añadirse que el trabajo intelectual es también, en parte, un trabajo que no escapa de lo manual. El intelectual o el empleado de una oficina pública o de un periódico se sienta y escribe a mano o con la ayuda de una máquina de escribir. Ese gesto, o mejor dicho, esa práctica es la que se invisibiliza tras la etiqueta de intelectual, de "hombre de ideas".

En su crónica "Ocio y trabajo", mencionada anteriormente, junto con ironizar la imagen del escritor improductivo, Cid también establece una distancia importante entre él, un empleado del diario La Nación, ex funcionario del Ministerio de Relaciones Exteriores, y el mundo obrero. $\mathrm{Su}$ trabajo centrado en las letras también instala una diferencia con el oficio de su padre: "este caballero, ferroviario antiguo, para que lo sepáis de una vez por todas" (4). Este "para que lo sepáis de una vez por todas" enfatiza el carácter de confesión y de eventual rumor sobre su origen social. En este sentido, es interesante que se ocupe de ese supuesto rumor e incluya en su crónica un comentario sobre lazos filiales en un contexto donde prima el rigor profesional y, además, el mérito. Cid se apropia del posible chisme, mecanismo recurrente en el espacio cultural latinoamericano por el cual se construye o destruye una imagen pública. Por ejemplo, en su crónica centrada en Miriam Hernández, en su libro Perlas y cicatrices (1998), Pedro Lemebel recurre a la cita de otra voces para reconstruir el camino hacia el éxito de la cantante: "Sin tener una gran voz, supo usar el molde femenino más tradicional, el más recatado, 'la chica pobre pero decente'" $(67)^{15}$. O en el caso de Alejo

15 En su artículo “Chile: Una loca geografía o las crónicas de Pedro Lemebel”, Ángeles Mateo del Pino plantea que "Lemebel atiende súplicas y se erige en portavoz de los desheredados, en mensajero de los caídos. Para ello utilizará todas las armas que le proporciona la escritura, cuya amplia gama lo llevará desde la biografía y el testimonio al 'pelambre' y el chisme (21). 
Carpentier, este se inmiscuye en la vida privada de Josephine Baker y en ese contexto se circunscribe a la escritura del "chisme", a pesar de sus intentos de autorizarse. Al inicio de su crónica intitulada "Confesiones de Josephine Baker" , el cronista señala que "lejos del público, cuando se hace innecesario sonreír, es cuando una actriz nos revela sus debilidades, sus taras y sus defectos" (397). De este modo, entra en la escritura de lo desconocido, de lo que no es público para sus lectores, y aprovecha de dar a conocer a otra Josephine Baker. En la crónica “El Éxodo de Josephine Baker", publicada 5 años después, el gesto del cronista que se inmiscuye en la vida privada de la figura pública se acentúa. Además, reaparece la Baker de las revistas, "el ser felino, de largas piernas bronceadas, de proporciones perfectas" (169). Y en vez de enfatizar la domesticidad impecable de la otrora bailarina, el cronista desliza comentarios que cuestionan la formación intelectual y los hábitos de la artista. Si en la crónica anterior la Baker no bebía alcohol, en esta lo que ella llama tomar el té es tomar Martini Seco (168). Si en su biblioteca se exhibe en hermosas ediciones de Molière, Voltaire, Cornèille, "la edición original de Las Flores del mal [y] De la divina comedia ilustrada por Doré", el cronista revela al lector que en verdad ella lee lo que tiene oculto en un estante: Josephine Baker lee las obras completas de Edgard Wallace: en escritor de policiales, novelas de misterio y escritor del guión de la película Kin-Kong. Edgard Wallace es un ejemplo del éxito de un autor propio de la cultura de masas. Es decir, Carpentier haciendo pública esa información adscribe claramente a la Baker en un ámbito cultural que todavía generaba dudas o, al menos confusiones, en cuanto a su valoración simbólica. Si en la primer crónica el cronista intenta matizar la figura pública "felina" de la Baker, en esta segunda retrocede y confirma la adscripción de la Baker a la cultura de masas y a la bohemia parisina. En este contexto, las crónicas de Carpentier son escrituras dubitativas que en las que el chisme se inscribe como recurso discursivo. Volviendo al caso de Cid, asimismo, la tensión entre la declaración ante sus lectores del oficio de su padre en contraste con su actual profesión, sintetiza la historia del ascenso social de algunos miembros de la clase media en Chile, porque si bien su padre era "ferroviario antiguo", este también "era propietario de una máquina de escribir" y, continúa el cronista, "yo me di cuenta de que había que aprovecharla. Me puse a escribir como un loco. Como un loco lo sigo haciendo todavía. Creo que, para hablar con honradez, ningún escritor verdadero podría declarar otra cosa" ("Ocio y trabajo" 4). Aquí Cid 
acentúa la posibilidad de la escritura como mecanismo de ascenso social, porque la máquina "había que aprovecharla". Entonces, esta crónica de Cid señala otro asunto importante para la formación de las clases medias chilenas, ya que no solo ser un empleado o funcionario lo ubicaba en ese lugar del mapa socio-cultural urbano, sino que también el saber escribir y, todavía más, darle uso a uno de los avances tecnológicos más emblemáticos de la profesionalización del escritor y de la construcción del imaginario sobre la oficina. Al mismo tiempo, destaca la producción serial. "[M]e puse a escribir como un loco", dice Teófilo Cid, aludiendo a la producción cotidiana de la crónica periodística, pero también no olvida imprimir su sello de recordar la figura del excéntrico, del dandy, el loco; en otras palabras, del bohemio. De este modo, el espacio del periódico le sirve para reafirmar su pose como dandy, es decir, como escritor de literatura, aunque en esa escritura también está el empleado. Por último, y en sintonía con lo mencionado páginas atrás mientras se citaba a Alone, Cid también entrega su fórmula, entrega el dato, la información que debe saber ese aspirante a escritor: se debe escribir como un loco porque "ningún escritor verdadero podría declarar otra cosa" ("Ocio y trabajo" 4). La locura de Cid como fórmula para llegar a ser escritor, por lo tanto, desarticula los métodos o pasos a los que hay que atenerse para conseguirlo. Sin embargo, la escritura en el contexto de la oficina, aunque tecnología básica para el funcionamiento de la administración pública, pierde también, debido a la burocracia, sentido. Las infidencias de las crónicas de Prieto sobre la vida dedicada al servicio público posicionan la escritura como un modo de producción vacío: "Fulano: ponga en orden esas cartas; clasifíquelas por orden alfabético y échelas en seguida a la basura" ("La voz olvidada" 123). En consecuencia, en la escritura de Prieto de El Diario Ilustrado, caracterizada por sus atributos dialógicos no solo con su potencial público lector, sino también por la incorporación de escenas de conversación en el espacio de la crónica, se genera un contrapunto entre la escritura útil del cronista en oposición al trabajo del burócrata. En este sentido, Prieto se asemeja al "intelectual accesible", que acompaña al lector en su experiencia de la vida cotidiana moderna del que habla Mahieux (2011) en su libro dedicado a los cronistas de los años veinte y treinta.

En Cid también es posible identificar una situación similar. En sus crónicas, a medida que pasa el tiempo, pareciera que poco a poco va 
creciendo el sentimiento de desencanto frente al ejercicio escritural. $\mathrm{Al}$ dar cuenta del sinsentido del acto de la escritura, Cid, a diferencia de Prieto que lo ubica en el servicio público, lo traslada a su oficio de cronista y recalca la desvinculación entre el periodista-empleado y su público lector (no así el poeta, que según Cid escribe para sí mismo). Como se mencionó anteriormente, ya en 1954 Cid se preguntaba públicamente por qué escribía y en su respuesta enfatiza las tensiones que hay entre política y escritura: “Por qué escribo? ¿Para quién escribo? Mi conciencia profesional, si es que la tengo, no es otra cosa que copia de ese acto inicial de hace veintisiete años. Tengo la impresión de que mi conciencia no está arrendada a nadie. No soy comunista, no soy partidario de nadie. Gózome, en cambio, refugiándome en mi propia vida" ("Por qué escribo" 4) ${ }^{16}$. Al final de su crónica, no obstante, recurre a las emociones y se instala como un intelectual que llora, "no hago otra cosa que llorar" ("Por qué escribo" 4), poniendo énfasis en la pose de desapego partidista que realiza un gesto político-sentimental.

Si en la crónica de Prieto y Cid la especialización, la afirmación de una identidad de clase y el modo de producción del empleado público permea la crónica, en las crónicas de Armando Méndez Carrasco estos atributos se tensionan o se presentan de otra forma. Méndez Carrasco escribe desde otro lugar, desde el margen más fino (o poroso) de la clase media. Conocido también como Juan Firula (quien también tuvo su propio sello editorial) autor de crónicas, cuentos y novelas, Méndez Carrasco se incorpora al Cuerpo de Carabineros de Chile para sobrevivir económicamente y "regenerarse" del mundo delictual por el cual sentía una incontrolable atracción. "Mi despertar se inició el día 12 de agosto de 1944, a las 11 de la mañana, es decir, en el mismo instante que puse papel en la Underwood y escribí mi primera crónica. Creo que sólo allí vine a darme cuenta qué había venido al planeta. Durante 28 años había existido como un pájaro, sumido en superlativa irresponsabilidad" ("En el viejo Olimpia" 11) señala el cronista Juan Firula. En este sentido, si a veces la escritura en prensa de Cid y Prieto revela la soledad del oficio, la incomprensión y la inutilidad, Méndez Carrasco ofrece una mirada mucho más optimista; en la escritura está la vida y está signada

16 Recordemos que en 1948 se promulgó lo que se conoce como la "Ley Maldita" bajo el gobierno de Gabriel González Videla. Junto con limitar las libertades individuales, entre otras restricciones, declaró la ilegalidad del Partido Comunista. La vigencia de esta ley se extendió hasta 1958. 
como una partida de nacimiento. Siguiendo esta idea, en otra crónica justificará su oficio aduciendo que: "Me he propuesto escribir una serie de crónicas autobiográficas, y cumpliré. No lo hago por vanidad, sino para que esta muestra sirva de algo y nadie imite" ("Un mundo alocado" 13). La alusión a la "vanidad" resuena con la idea de escribir por moda, según se comentaba en páginas anteriores, porque escribir tiene un aura que no tienen otros oficios. Juan Firula aquí asume la figura de escritor advenedizo rechazada por $\mathrm{Cid}$, e intenta darle una cariz profesionalizante al destacar que ese renacer a la vida se produce no solo escribiendo una crónica que sería publicada en el periódico, sino frente a una Underwood, es decir, apela al uso de la tecnología. Asimismo, traslada a otro espacio la figura del empleado público. En este sentido, la escritura periodística de Juan Firula contrasta con la de Prieto y Cid porque está teñida por un enfoque de "servicio público", en el cual enmarca su advertencia a los lectores sobre la forma en que no se debe vivir. Es decir, se conecta con sus lectores desde las emociones. Sus crónicas adquieren connotaciones "terapéuticas" y de "salvación": son una forma de sanarse, de mantenerse lejos del mundo delictual. "Cuando me propuse escribir algunas crónicas para los amables lectores de 'Las Últimas Noticias' estimé que sería beneficioso dar a conocer pedazos de una vida auténtica- No es tan fácil; en todo caso estas líneas me reportan un gran descanso espiritual" ("Pasos ministeriales" 35-36). Se podría decir que Juan Firula ingresa al mundo de la escritura por razones similares a las que ingresa al Cuerpo de Carabineros, motivos de sobrevivencia y regeneración. Y, hasta cierto punto lo logra:

Resulta que, de súbito, me hallé desempeñando un puesto nada menos que en la Subsecretaría de Educación. Para mí, que pensaba morir como un modesto dactilógrafo, fue un ascenso más que contundente, pues mi desprestigio, debido a un desorden absolutamente "normal", era de tales proporciones, que ningún alma habría dado una "chaucha" por mi pellejo. Los diez años que habría pertenecido al Cuerpo de Carabineros de Chile me rectificaron, mas no lo suficiente. (36)

Ahora bien, si el acto de escritura en Prieto y Cid aparece por momentos como un ejercicio monótono o carente de propósito vinculado a la figura del empleado, del oficinista o del cronista que no sabe para qué o quién 
escribe, Juan Firula se apropia del imaginario de la escritura profesional por medio de la Underwood, pero traslada el origen de su escritura a un acto de denuncia que delimita su lugar de enunciación: una clase media frágil, desprotegida y en su contexto laboral, subordinada:

[...] la mañana del citado día tuve una mala noticia: mi amigo carabinero había sido destrozado por una camioneta que corría velozmente por Bilbao. Eso me impresionó y como el causante del delito quedó en libertad a las pocas horas, por ser alto empleado del Gobierno, me dolió. Me afectó la injusticia. Me rebelé.

Sólo en ese momento moví la máquina y nació la primera crónica; fue un artículo muy amargo que me publicó un diario de la tarde. ("En el viejo Olimpia" 11)

En ese sentido, según declara Méndez Carrasco -y si se le cree-, se inició en la escritura periodística movilizado por los afectos, pero también se presenta como un potencial justiciero. La escritura, entonces, funciona ya no tanto como mecanismo de sobrevivencia económica sino emocional, dando un giro en contraste a Prieto y a Cid. Es así como Méndez Carrasco se inicia en el periodismo, pues su contexto laboral para entonces era Carabineros de Chile. Su oficio se filtra en su escritura de otro modo, es la experiencia de la subordinación que lo impulsa a sentarse a escribir y lograr que le publiquen la crónica. Aunque finalmente señale que esa "emoción [la] compartí en soledad", porque "nadie me creyó", "[m]e tenían por un desharrapado" (12). La publicación de su texto en la prensa indica un pequeño ascenso en la valoración de su persona; no obstante, las ambiciones del cronista estaban lejos ser profesionales o con miras de un ascenso social.

En el "lado B" de la escritura convive la figura del cronista y la del empleado, revelando no sólo la escritura como un medio de ascenso o identificación social, sino también configurando un imaginario de escritor y periodista que no necesariamente están en tensión y que se construye desde la figura del empleado. Es así que este corpus también contribuye a la comprensión tanto de la especialización de la escritura como de las resonancias de la profesionalización del escritor. Al mismo tiempo, aunque por momentos se da cuenta de cierta insatisfacción ya sea por la inutilidad de su escritura o por no tener claridad en cuanto a 
la recepción de su producción, la posición de cronistas los dota de cierta autoridad en el amplio ámbito de la escritura, dentro del cual se pueden acomodar como empleados, burócratas, servidores públicos, pero también desde las emociones. Desde ese heterogeneidad, los cronistas revelan un imaginario sobre la tecnología y la escritura a la vez que ofrecen una valoración de su oficio que contrasta con los consejos que Alone y Joaquín Edwards Bello comparten con sus lectores.

\section{Referencias Bibliográficas}

Aguilar, Óscar y Julia Antivilo. Historia de la Sociedad de Escritores de Chile. Los diez primeros años de la SECH y visión general 19312001. Santiago: Sociedad de Escritores de Chile, 2002.

Arlt, Roberto. “¿Cómo quieren que les escriba?” Obras completas. Tomo 2. Buenos Aires: Losada, 2011. 370-373.

Barajas, María Josefina. Textos con salvoconducto: La crónica periodísticoliteraria venezolana de finales del siglo XX. Colección Arte y Literatura. Caracas: Universidad Central de Venezuela; Ediciones de la Biblioteca-EBUC; Comisión de Estudios de Postgrado; FHE, 2013.

Candina Polomer, Azun. Clase media, Estado y sacrificio: la Agrupación Nacional de Empleados Fiscales en Chile contemporáneo (1943-1983). Santiago: LOM ediciones, 2013.

Candina, Azun. Por una vida digna y decorosa. Clase media y empleados públicos en el siglo XX chileno. Santiago: Esfera de Papel Libros, 2009.

Carpentier, Alejo. "Confesiones de Josephine Baker". Obras completas. Tomo IX. Crónicas 2. Arte, literatura y politica. 397-403. Impreso.

. "El éxodo de Josephine Baker". Crónicas del regreso. La Habana, Cuba: Editorial Letras Cubanas, 2002. 167-170.

Catalán, Gonzalo. "Antecedentes sobre la transformación del campo literario en Chile entre 1890 y 1920". Eds. J.J. Brunner 
y G. Catalán. Cinco estudios sobre cultura y sociedad. Santiago: FLACSO, 1985. 71-175.

Cid, Teófilo. ¡Hasta Mapocho no más! Santiago: Nascimento, 1976. . "La 'desvirtuación' profesional". La Nación 1 junio 1955: 4. . “Nadie sabe para quién escribe...". La Nación 2 mayo 1958: 4. . “Ocio y trabajo". La Nación 1 mayo 1955: 4. . "Por qué escribo". La Nación 27 octubre 1954: 4.

De Paola, Luis. “Retratos de un coleccionista pobre. Teófilo Cid". Plan 118 (30 de agosto 1973): 18.

Del Pino, Ángeles Mateo. “Chile: Una loca geografía o las crónicas de Pedro Lemebel”. Hispamérica 27.80-81 (1998):17-28.

Díaz Arrieta, Hernán. Alone. El vicio impune (50 años de crónicas). Selección y prólogo de Alfonso Calderón. Santiago de Chile: Ril editores, 1997.

___. "La carrera literaria". El vicio impune..., 241-243.

. "Distintas maneras de escribir mal". El vicio impune..., 129-132.

. "Matar su alma". El vicio impune..., 65-69.

. "El misterio de escribir". El vicio impune..., 35-38.

. “La tentación literaria”. El vicio impune..., 111-119.

. "Trabajar el estilo". El vicio impune..., 43-46.

Edwards Bello, Joaquín. En torno al periodismo y otros asuntos. Selección y prólogo de Alfonso Calderón. Santiago de Chile: Editorial Andrés Bello, 1969.

. "A un cronista". En torno al periodismo...., 93-96.

. "Consejos al joven que desearía ser escritor". En torno al periodismo..., 47-51.

. "No embrollemos la vida". La Nación 5 enero 1940: 4.

Espinoza, Enrique. "El diario, la revista, el libro". De un lado y otro. Santiago de Chile: Universitaria. 9-15. 
González, Aníbal. La crónica modernista hispanoamericana. Madrid: José Porrúa Turanzas, 1983.

Lemebel, Pedro. "Miriam Hernández (o "una canción de amor en la ventana del bloque")De perlas y cicatrices. Crónicas radiales. Chile: Lom, 1998. 66-68.

Lispector, Clarice. Revelación de un mundo. Buenos Aires: Adriana Hidalgo, 2010.

"Los jueves de Joaquín Edwards Bello". Memoria Chilena. Biblioteca Nacional de Chile. Web. 10 Oct 2015.

Mahieux, Viviane. Urban Chroniclers in Modern Latin America. The Shared Intimacy of Everyday Life. Austin: University of Texas Press, 2011.

Méndez Carrasco, Armando. Crónicas de Juan Firula. Santiago: Ediciones de la Librería Renacimiento, 1965.

. “En el viejo Olimpia”. Crónicas...., 7-12.

. “Un mundo alocado". Crónicas..., 13-17.

. “Pasos ministeriales". Crónicas..., 35-39.

Prieto, Jenaro. “Académicos". Pluma en ristre. Santiago: Imprenta Chile, 1925. 51-53.

. "Humo de pipa...". Humo de pipa. Santiago: Editorial del Pacífico, 1955. 9-10.

. "La voz olvidada". Con Sordina. 2a edición. Santiago: Editorial Nascimento, 1930. 121-124.

Pron, Patricio. El libro tachado. Prácticas de la negación y del silencio en la crisis de la literatura. Madrid: Turner Publicaciones, 2014.

Ramos, Julio. Desencuentros de la modernidad en América Latina: literatura y politica en el siglo XIX. Santiago de Chile: CallejónCuarto Propio, 1989-2003.

Rotker, Susana. La invención de la crónica. Buenos Aires: Fondo de Cultura Económica, 2005. 